\title{
Uso de haces electrónicos de alta energía para esterilizar las aguas negras municipales del distrito Lunahuaná
}

\author{
Using high energy electron beams to esterilize \\ municipal sewage district Lunahuaná
}

\section{Parte II: Viabilidad económica para la descontaminación eficiente}

\author{
Recibido: 03/08/2015 Revisado: 12/08/2015 Aceptado: 09/09/2015
}

\author{
Benigno Benito Lizárraga Zavaleta', Carlos Job Fiestas Urbina², \\ Francisco Bautista Loyola ${ }^{2}$, Cayo Eduardo Guerra Lazo ${ }^{1}$
}

\section{RESUMEN}

Objetivo: Agregar valor a los efluentes y lodos de los sistemas de tratamiento de aguas residuales aplicando la tecnología de haces electrónicos de alta energía para una adecuada disposición y uso, disminuyendo los problemas ambientales y de salud de la población del distrito Lunahuaná. Métodos: Se utilizó el tipo de investigación aplicada no experimental, para resolver el problema de saneamiento eficiente de las aguas residuales municipales y lodos de los sistemas de tratamiento. Se analizó los diferentes tipos de costos económicos de las acciones de la alternativa propuesta para la ejecución del proyecto. Resultados: Se determinó una inversión inicial de S/.20'557 721,2 para la planta de irradiación con haces de electrones de mediana energía, la red troncal de alcantarillado, sistema de tratamiento biológico de aguas residuales, tanque colector, tanque de homogenización y estación de bombeo. El costo unitario de tratamiento por $\mathrm{m}^{3}$ de agua residual se estimó en S/.16,00, así mismo se ha determinado un costo total de operación anual de (S/./año) 4'117 566,00 que incluye la amortización anual del préstamo para la inversión inicial. Los ingresos por ventas de bioabono esterilizado, en el horizonte de 20 años, alcanzan un valor total actualizado de S/. 148'131 338,73. Conclusiones: Los ingresos anuales por venta de bioabono esterilizado son mayores que los costos de operación anual, lo cual permite cumplir los objetivos del proyecto

Palabras clave: Bioabono esterilizado, inversión inicial, costo de operación, costo unitario.

\section{ABSTRACT}

Objective: Adding value to effluent and sludge treatment systems wastewater technology using high-energy electron beams for proper disposal and use, reducing environmental and health problems of the people of Lunahuaná district. Methods: the type of applied research is not experimental, was used to solve the problem of efficient disposal of municipal and sludge from wastewater treatment systems. The different types of economic costs of the actions of the alternative proposal for the project implementation was analyzed. Results: An initial investment of was determined S/. 20'557 721.2 plant for electron beam irradiation of medium energy, trunk sewers, biological treatment system of wastewater collection tank, equalization tank and pumping station. The unit cost of treatment per $\mathrm{m}^{3}$ of wastewater was estimated at S/.16.00, also has given a total annual cost of operation (S/./ year) 4'117 566.00 which it includes the annual amortization of the loan to the initial investment. Sales revenue bioabono sterilized in the horizon of 20 years, reaching a total present value of $\mathrm{S} /$. 148'131 338.73. Conclusions: The annual income from the sale of sterilized bioabono outweigh the annual operating costs, enabling meet project objectives.

Keywords: Bioabono sterilized, initial investment, operating cost, unit cost.

\section{RESULTADOS}

Inversión inicial

La inversión inicial la clasificaremos según el componente del sistema.

1. Inversión inicial de la planta de irradiación y producción de bioabono

1.1. Material y equipamiento de la planta de irradiación y producción de bioabono 
Tabla 7. Materiales y equipos de la planta de irradiación y producción de bioabono.

\begin{tabular}{|c|c|c|c|c|}
\hline Materiales y equipos & Unidad & Cantidad & $\begin{array}{l}\text { Precio Unitario } \\
\text { (S/.) }\end{array}$ & $\begin{array}{l}\text { Costo } \\
\text { (S/.) }\end{array}$ \\
\hline $\begin{array}{l}\text { Acelerador de electrones, } \\
100 \mathrm{KW}, 5 \mathrm{MeV}\left(^{*}\right)\end{array}$ & Equipo & 2 & 4173000,00 & $8,346000,0$ \\
\hline Sistema de control $\left({ }^{*}\right)$ & Sistema & 2 & 973700,00 & $1^{\prime} 947400,0$ \\
\hline Sistema de monitoreo de radiaciones $\left({ }^{*}\right)$ & Sistema & 2 & 197740,00 & 395480,0 \\
\hline Edificaciones $\left({ }^{*}\right)$ & Edificio & 2 & 1669200,00 & $3{ }^{\prime} 338400,0$ \\
\hline Camioneta Pick up 4x4 & Unidad & 1 & 83460,00 & 83460,0 \\
\hline Camión cistena de bioabono, $5 \mathrm{~m}^{3}$ & Unidad & 1 & 222560,00 & 222560,0 \\
\hline Depósito de bioabono líquido & Unidad & 1 & 500000,00 & $\begin{array}{r}500000,0 \\
14^{\prime} 8333000\end{array}$ \\
\hline
\end{tabular}

Tipo de cambio: USA $\$ 1,00=\mathrm{S} / .2,782$ (nuevos soles)

(*) Fuente: Electron beam tecnology ebTech 550 yongsan-dong Yuseong-gu, Daejeon 305-500, Korea, (2009).

\subsection{Inversión de servicios diversos de la planta de irradiación y producción de bioabono}

Tabla 8. Inversión de servicios diversos de la planta de irradiación y producción de bioabono.

\begin{tabular}{|c|c|c|c|c|}
\hline Materiales y equipos & Unidad & Cantidad & $\begin{array}{l}\text { Precio Unitario } \\
\text { (S/.) }\end{array}$ & $\begin{array}{l}\text { Costo } \\
\text { (S/.) }\end{array}$ \\
\hline $\begin{array}{l}\text { Consultoría: Elaboración de } \\
\text { un perfil SNIP }\end{array}$ & Estudio & 1 & 60000,00 & 60000,00 \\
\hline $\begin{array}{l}\text { Conultoría: Elaboración de } \\
\text { un estudio de factibilidad SNIP }\end{array}$ & Estudio & 1 & 80000,00 & 80000,00 \\
\hline $\begin{array}{l}\text { Consultoría: Elaboración del } \\
\text { expediente técnico }\end{array}$ & Estudio & 1 & 140000,00 & 140000,00 \\
\hline $\begin{array}{l}\text { Consultoría: Estudio de } \\
\text { impacto ambiental }\end{array}$ & Estudio & 1 & 50000,00 & 50000,00 \\
\hline Licenciamiento de la instalación & Estudio & 1 & 50000,00 & 50000,00 \\
\hline Puesta en marcha de la planta & Operación & 1 & $\begin{array}{l}50000,00 \\
\text { Total: } \mathbf{S} / .\end{array}$ & $\begin{array}{r}50000,00 \\
430000,00\end{array}$ \\
\hline
\end{tabular}

Tipo de cambio: USA $\$ 1,00=\mathrm{S} / .2,782$ (nuevos soles)

(*) Fuente: Electron beam tecnology ebTech 550 yongsan-dong Yuseong-gu, Daejeon 305-500, Korea, (2009).

Tabla 9. Inversión inicial de la planta de irradiación y producción de bioabono.

\begin{tabular}{lrr}
\hline Descripción & Costo (S/.) \\
\hline 1.1 Material y equipamiento & $14^{\prime} 833300,00$ \\
1.2 Servicios diversos & 430000,00 \\
& Total: S/. & $15^{\prime} 263300,00$ \\
\hline
\end{tabular}

Fuente: Elaboración propia, de tablas 7 y 8.

2. Inversión inicial de la red troncal de alcantarillado (22 Km aproximado)

2.1 Materiales y equipamiento de la red troncal de alcantarillado (22 $\mathrm{Km}$ aproximado)

Tabla 10. Inversión inicial en materiales y equipamiento de la red troncal de alcantarillado (22 Km).

\begin{tabular}{|c|c|c|c|c|}
\hline Materiales y equipos & Unidad & Cantidad & $\begin{array}{c}\text { Precio Unitario } \\
\text { (S/.) }\end{array}$ & $\begin{array}{c}\text { Inversión/ITEM } \\
\text { (S/.) }\end{array}$ \\
\hline $\begin{array}{l}\text { Tubo PVC, } \Phi=2 ", L=3 \mathrm{~m} \\
\text { Tubo PVC, } \Phi=4 ", L=3 \mathrm{~m} \\
\text { Tubo PVC, } \Phi=6 ", L=5 \mathrm{~m} \\
\text { Codo PVC, } \Phi=2 ", 90^{\circ} \\
\text { Codo PVC, } \Phi=4 ", 90^{\circ} \\
\text { Codo PVC, } \Phi=6 ", 90^{\circ} \\
\text { Buzón colector, incluye mano de } \\
\text { obra, materiales y equipos }\end{array}$ & $\begin{array}{l}\text { Tubo } \\
\text { Tubo } \\
\text { Tubo } \\
\text { Codo } \\
\text { Codo } \\
\text { Codo } \\
\text { Buzón }\end{array}$ & $\begin{array}{r}734 \\
3918 \\
1930 \\
25 \\
110 \\
80 \\
112\end{array}$ & $\begin{array}{r}10,50^{(1)} \\
21,00^{(1)} \\
78,00^{(1)} \\
1,40^{(1)} \\
5,60^{(1)} \\
48,00^{(1)} \\
1445,00^{(1)} \\
\text { Total: Sl. }\end{array}$ & $\begin{array}{rr}7 & 707,00 \\
82 & 278,00 \\
150 & 540,00 \\
35,00 \\
616,00 \\
3840,00 \\
161840,00 \\
406856,00\end{array}$ \\
\hline
\end{tabular}

(1) Fuente: Constructora Grupo S10, “Costos construcción arquitectura e ingeniería” (2013). 
2.2 Servicios diversos de la red troncal de alcantarillado

Tabla 10. Inversión inicial en servicios diversos de la red troncal de alcantarillado (22 Km).

\begin{tabular}{|c|c|c|c|c|}
\hline Descripción del ítem & Unidad & Cantidad & $\begin{array}{l}\text { Precio Unitario } \\
\text { (S/.) }\end{array}$ & $\begin{array}{l}\text { Costo } \\
\text { (S/.) }\end{array}$ \\
\hline $\begin{array}{l}\text { Excavación con máquina, terreno } \\
\text { semirocoso, } H=1 m \text {, Tub. } \Phi_{i n}=2 "\end{array}$ & $(\mathrm{~m})$ & 2202 & $6,09^{(1)}$ & 13410,18 \\
\hline $\begin{array}{l}\text { Excavación con máquina, terreno } \\
\text { semirocoso, Tub. } \Phi_{\text {in }}=4 "\end{array}$ & $(\mathrm{~m})$ & 11754 & $7,30^{(1)}$ & 85804,20 \\
\hline $\begin{array}{l}\text { Exacavación con máquina, terreno } \\
\text { semirocoso, } H=1 \mathrm{~m} \text {, Tub. } \Phi_{\text {int }}=6 "\end{array}$ & (m) & 9650 & $7,30^{(1)}$ & 70445,00 \\
\hline $\begin{array}{l}\text { Relleno compactado para zanja, terreno } \\
\text { semirocoso, } H=1 \mathrm{~m} \text {, Tub. } \Phi_{N}=2 "\end{array}$ & (m) & 2202 & $28,01^{(1)}$ & 61678,02 \\
\hline $\begin{array}{l}\text { Relleno compactado para zanja, terreno } \\
\text { semirocoso, } \mathrm{H}=1 \mathrm{~m} \text {, Tub. } \Phi_{N}=4 "\end{array}$ & $(\mathrm{~m})$ & 11754 & $34,44^{(1)}$ & 404807,76 \\
\hline $\begin{array}{l}\text { Relleno compactado para zanja, terreno } \\
\text { semirocoso, } H=1 \mathrm{~m} \text {, Tub. } \Phi_{N}=6 "\end{array}$ & (m) & 9650 & $34,44^{(1)}$ & 332346,00 \\
\hline Instalación y prueba hidráulica, Tub. $\Phi_{N}=2 "$ & (m) & 2202 & $8,40^{(2)}$ & 18496,80 \\
\hline Instalación y prueba hidráulica, Tub. $\Phi_{N}=4 "$ & (m) & 11754 & $8,40^{(2)}$ & 98733,60 \\
\hline Instalación y prueba hidráulica, Tub. $\Phi_{N}=6 "$ & (m) & 9650 & $8,40^{(2)}$ & 81060,00 \\
\hline Consultoría: Elaboración de un perfil SNIP & Estudio & 1 & 20000,00 & 20000,00 \\
\hline Consultoría: Expediente técnico & Estudio & 1 & $\begin{array}{r}100000,00 \\
\text { Total S/. }\end{array}$ & $\begin{array}{r}100000,00 \\
1^{\prime} 286781,56\end{array}$ \\
\hline
\end{tabular}

(1) Fuente: Constructora Grupo S10, “Costos construcción arquitectura e ingeniería" (2013).

(2) Fuente: Moreno Sotomayor, J. B. (2010).

Tabla 11. Inversión inicial total en la red troncal de alcantarillado.

\begin{tabular}{lrr}
\hline \multicolumn{1}{c}{ Descripción } & Costo (S/.) \\
\hline 2.1 Material y equipamiento & & 406856,00 \\
2.2 Servicios diversos & Total: S/. & $1^{\prime} 286781,56$ \\
& T'637,56 \\
\hline
\end{tabular}

Fuente: Elaboración propia, de tablas 10 y 9

3. Inversión inicial del sistema de tratamiento biológico y primario de aguas residuales municipales.

Tabla 12. Inversión inicial del sistema de tratamiento biológico y primario de aguas residuales municipales.

\begin{tabular}{lrr}
\hline \multicolumn{1}{c}{ Descripción } & Costo (S/.) \\
\hline 3.1 Material y equipamiento & & 2 '203 233,60 \\
3.2 Servicios diversos & Total: S/. & $\mathbf{2}^{\prime} 43323000,00$ \\
& 233,60 \\
\hline
\end{tabular}

Fuente: Elaboración propia

Siguiendo el mismo procedimiento se ha estimado y obtenido, finalmente:

Tabla 13. Inversión inicial.

\begin{tabular}{lr}
\hline \multicolumn{1}{c}{ Descripción } & Costo (S/.) \\
\hline $\begin{array}{l}\text { 1. Planta de irradiación y producción } \\
\text { de bioabono }\end{array}$ & $15^{\prime} 263300,00$ \\
$\begin{array}{l}\text { 2. Red troncal de aguas residuales } \\
\text { tratadas }\end{array}$ & $1^{\prime} 693367,56$ \\
$\begin{array}{l}\text { 3. Sistema de tratamiento biológico } \\
\text { de aguas residuales municipales }\end{array}$ & $2^{\prime} 433253,60$ \\
$\begin{array}{l}\text { 4. Tanque colector, tanque de } \\
\text { homogenización y estación }\end{array}$ & $1^{\prime} 167800,00$
\end{tabular}
de bombeo

Total: S/. $20^{\prime} 557721,16$

\section{Costos operativos anuales fijos}

Amortización del préstamo bancario: La inversión inicial M (20`557 721,2), será financiada a través de un préstamo bancario sometido a un interés anual I $=9 \%$, por un período $\mathrm{n}=20$ años.

El monto anual fijo que se debe amortizar para cancelar la deuda (AAN), según Andrade Espinoza (2002), se calcula mediante la siguiente fórmula financiera.

$$
\mathrm{AAN}=\frac{M\left(1+\frac{\mathbf{I}}{100 \%}\right)^{\mathrm{n}}\left(\frac{\mathbf{I}}{100 \%}\right)}{\left(1+\frac{\mathbf{I}}{100 \%}\right)^{\mathrm{n}}-1}=2252053,3
$$

Costos operativos anuales fijos

Tabla 14. Resumen de costos operativos anuales fijos, (COAF).

\begin{tabular}{lr}
\hline \multicolumn{1}{c}{ Descripción } & Costo (S/.) \\
\hline $\begin{array}{l}\text { Amortización anual fija } \\
\text { de la deuda (AAN) }\end{array}$ & 2 '252 053,30 \\
$\begin{array}{l}\text { Costos operativos } \\
\text { laborales fijos }\end{array}$ & 596000,00 \\
Depreciación anual & 313474,06
\end{tabular}

Total: S/. 3'163 527,36 


\section{Costos operativos anuales variables}

Tabla 14. Costos de mantenimiento.

\begin{tabular}{lccc}
\hline \multicolumn{1}{c}{ Descripción } & $\begin{array}{c}\text { Inversión } \\
\text { (S/.) }\end{array}$ & $\begin{array}{c}\text { Porcentaje de la Inversión } \\
\text { (\%) }\end{array}$ & $\begin{array}{c}\text { Costo anual de } \\
\text { mantenimiento (S/.)/año }\end{array}$ \\
\hline $\begin{array}{l}\text { Red troncal de aguas residuales } \\
\text { tratadas }\end{array}$ & $1^{\prime} 693367,56$ & 3 & 50801,03 \\
$\begin{array}{l}\text { Sistema de tratamiento biológico de } \\
\text { aguas residuales municipales }\end{array}$ & $2{ }^{\prime} 433253,60$ & 3 & 72997,61 \\
$\begin{array}{l}\text { Tanque colector, tanque de } \\
\text { homogenización y estación de bombeo }\end{array}$ & $1^{\prime \prime} 167800,00$ & 3 & 35034,00 \\
$\begin{array}{l}\text { Planta de irradiación y producción de } \\
\text { bioabono }\end{array}$ & 15,263 300,00 & 2 & 305266,00 \\
& $\mathbf{2 0}$ '557 721,16 & (S/./año): & $\mathbf{4 6 4 0 9 8 , 6 4}$ \\
\hline
\end{tabular}

Fuente: Elaboración propia

Tabla 15. Resumen de costos operativos anuales variables, (COAV).

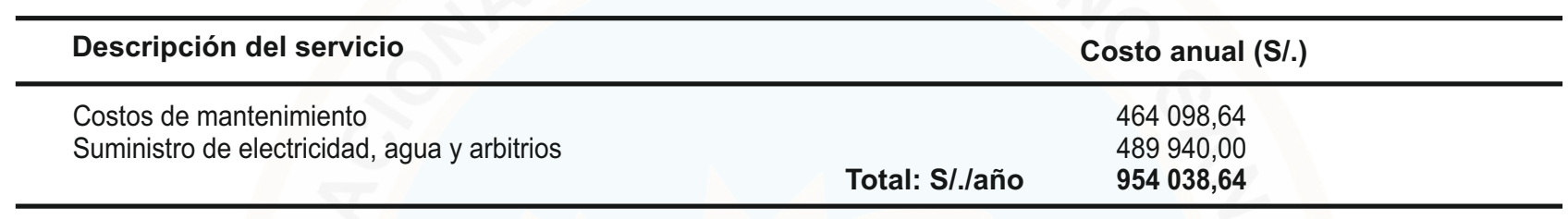

Fuente: Elaboración propia

\section{Costos operativos anuales totales}

Tabla 16. Resumen de costos operativos anuales totales, (COAT).

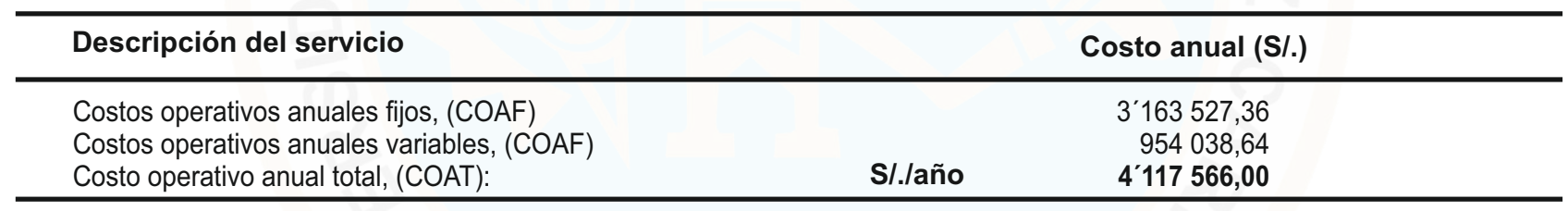

Fuente: Elaboración propia

\section{Costos operativos totales unitarios}

Reportaremos el costo operativo total unitario (COTU), que corresponde al horizonte del proyecto, cuando la población es de 6900 (habitantes) y el volumen de tratamiento de agua residual es 707,21 ( $\mathrm{m}^{3} /$ día). Se obtiene dividiendo el costo operativo anual total (COAT) entre el volumen de tratamiento de aguas residuales realizado durante el año.

$$
\text { COTU }=\frac{\text { COAT }}{\text { VAT }}=\frac{4^{\prime} 117566,00\left(\frac{\mathrm{S} /}{\text { año }}\right)}{707,21\left(\frac{\mathrm{m}^{3}}{\text { día }}\right)\left(\frac{365,25 \text { día }}{\text { año }}\right)}=16\left(\frac{\mathrm{S} / .}{\mathrm{m}^{3}}\right)
$$

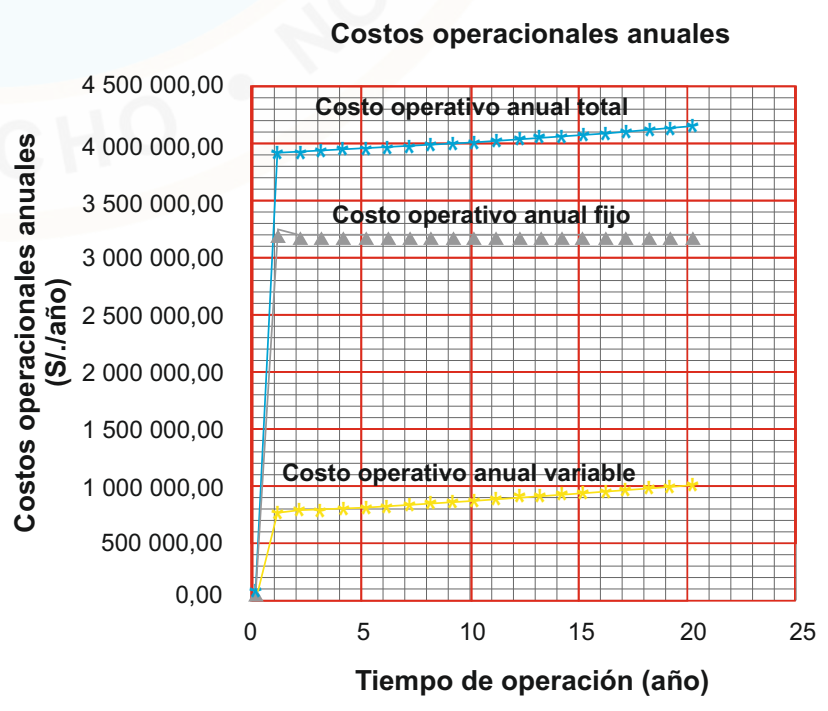

Figura 10. Costos operativos anuales en el horizonte del proyecto 


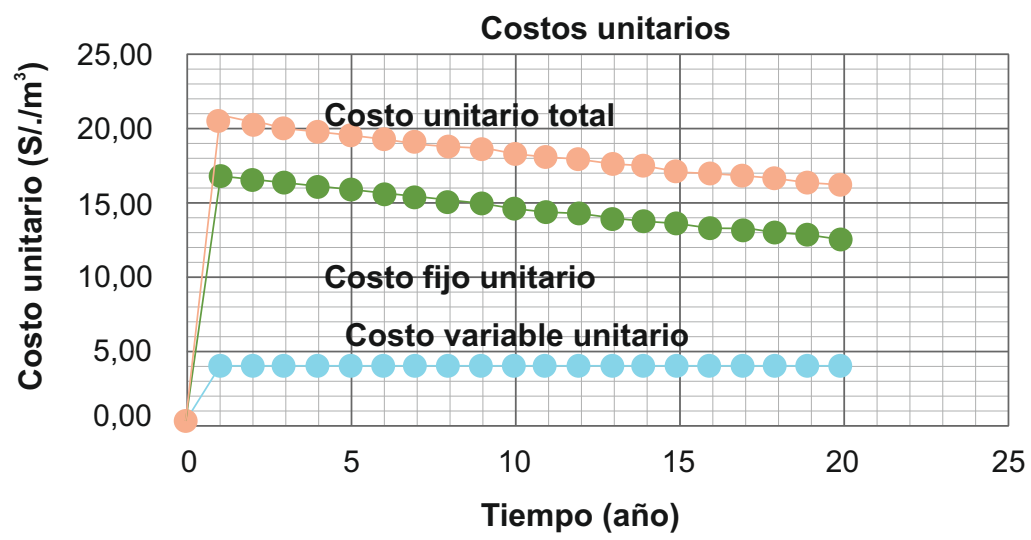

Figura 11. Costos unitarios en el horizonte del proyecto.

Valoración del bioabono producido en la planta de tratamiento de aguas residuales (PTAR), ingresos y beneficios sociales

En el distrito de Lunahuaná para el año 2033, se estima un caudal de depuración de 707,21 ( $\mathrm{m}^{3} /$ día), según datos estimados en unidades previas del presente estudio. Este volumen de agua llega a las estaciones depuradoras de aguas residuales (tanques Imhoff), a través de colectores. La presencia de tipos de contaminantes muy variados en las aguas residuales urbanas obliga a realizar tratamientos específicos de las mismas.

Los tratamientos propuestos son de tipo mecánico, biológico e irradiación, y componen el pretratamiento, tratamiento primario, e irradiación.
Después de obtener el caudal de agua depurada, en tanques Imhoff, se producen residuos generados por el proceso de depuración. Dichos residuos son denominados los fangos o lodos de depuración, los cuales se vuelven a mezclar con el agua depurada. El objetivo principal del tratamiento primario (tanques Imhoff) es la digestión parcial de los sólidos digeribles de las aguas residuales municipales. Estas aguas tratadas a nivel primario se homogenizarán y luego serán sometidas a un proceso de desinfección por irradiación con haces electrónicos de mediana energía, convirtiéndose en un valioso bioabono líquido por su alto contenido de nutrientes para los cultivos de la zona agrícola.

Tabla 17. Aporte per cápita de constituyentes de aguas residuales municipales (g/hab/día).

\begin{tabular}{|c|c|c|c|c|c|}
\hline \multirow{2}{*}{ Constituyente } & \multicolumn{3}{|c|}{ Estado } & \multirow{2}{*}{ DBO } & \multirow{2}{*}{ DQO } \\
\hline & Mineral & Orgánico & Total & & \\
\hline $\begin{array}{l}\text { Sólidos suspendidos } \\
\text { Sedimentables } \\
\text { No sedimentables } \\
\text { Sólidos disueltos } \\
\text { Sólidos totales } \\
\text { Nitrógeno amoniacal } \\
\text { Nitrógeno total } \\
\text { Fósforo total } \\
\text { Detergente } \\
\text { Cloruros } \\
\text { Potasio }\end{array}$ & $\begin{array}{r}25 \\
15 \\
10 \\
80 \\
105\end{array}$ & $\begin{array}{r}65 \\
39 \\
26 \\
80 \\
145\end{array}$ & $\begin{array}{r}90(36,00 \%) \\
54(21,60 \%) \\
36(14,40 \%) \\
160(64,00 \%) \\
250(100 \%) \\
3,0 \text { a } 10,0 \\
6,0 \text { a } 12,0 \\
1,0 \text { a } 8,0 \\
7,0 \text { a } 12,0 \\
5,0 \text { a } 10,0 \\
2,0 \text { a } 6,0\end{array}$ & $\begin{array}{r}42(77,8 \%) \\
19(35,2) \\
23(42,6 \%) \\
12(22,2) \\
54(100 \%)\end{array}$ & $\begin{array}{c}41(71,9 \%) \\
16(28,1 \%) \\
25(43,9 \%) \\
16(28,1 \%) \\
57(100 \%)\end{array}$ \\
\hline Microorganismos & & (Bact/hab/día) & (Bact/hab/día) & & \\
\hline $\begin{array}{l}\text { Bacterias totales } \\
\text { Coliformes } \\
\text { Termotolerantes } \\
\text { Coliformes totales } \\
\text { Estreptococo fecal } \\
\text { Salmonella typhosa } \\
\text { Clostridium } \\
\text { Pseudomona auruginosa } \\
\text { Bífido bacterium } \\
\text { Bacteroides spp } \\
\text { Quistes de protozoarios } \\
\text { Huevos de helmintos } \\
\text { Virus (UFP) }\end{array}$ & & $\begin{array}{l}\text { 10E11 - 10E12 } \\
\text { 10E08 - 10E11 } \\
\text { 10E09 - 10E11 } \\
\text { 10E07 - 10E10 } \\
\text { 10E01 - 10E04 } \\
\text { 10E03 - 10E09 } \\
\text { 10E05 - 10E07 } \\
\text { 10E10 - 10E13 } \\
\text { 10E10 - 10E13 } \\
\text { 10E01 - 10E03 } \\
\text { 10E01 - 10E03 } \\
\text { 10E02 - 10E04 }\end{array}$ & $\begin{array}{l}\text { 10E11 - 10E12 } \\
\text { 10E08 - 10E11 } \\
\text { 10E09 - 10E11 } \\
\text { 10E07 - 10E10 } \\
\text { 10E01 - 10E04 } \\
\text { 10E03 - 10E09 } \\
\text { 10E05 - 10E07 } \\
\text { 10E10 - 10E13 } \\
\text { 10E10 - 10E13 } \\
\text { 10E01 - 10E03 } \\
\text { 10E01 - 10E03 } \\
\text { 10E02 - 10E04 }\end{array}$ & & \\
\hline
\end{tabular}

Fuente: Rojas Vargas, Ricardo, (2002). 
Composición estimada del bioabono líquido producido

Las sustancias consideradas fertilizantes contenidas en los efluentes de aguas residuales domésticas son esencialmente las siguientes: Nitrógeno $(\mathrm{N})$, fósforo $(\mathrm{P})$ y potasio $(\mathrm{K})$, considerados macronutrientes de las plantas.

Las plantas absorben al nitrógeno en forma de iones nitrato $\left(\mathrm{NO}_{3}^{-}\right)$y amonio $\left(\mathrm{NH}_{4}^{+}\right)$, el fósforo es absorbido en forma de iones fosfato $\left(\mathrm{PO}_{4}^{-3}\right)$ y fosfato ácido $\left(\mathrm{HPO}_{4}^{-2}\right)$, y el potasio es absorbido en su forma iónica $\left(\mathrm{K}^{+1}\right)$.
El tanque Imhoff elimina del $40 \%$ al $50 \%$ de sólidos suspendidos y reduce la DBO de $25 \%$ a $35 \%$. Los lodos acumulados en el digestor del tanque Imhoff se extraen periódicamente y se conducen a lechos de secado. En nuestro caso estos lodos se recombinarán con el efluente para su desinfección conjunta.

El proceso de digestión no altera el contenido total de las sustancias consideradas macronutrientes $(\mathrm{N}, \mathrm{P}, \mathrm{K})$. Asimismo, el proceso de irradiación no afecta a estos componentes, en consecuencia podemos elaborar siguiente tabla 18, de contenidos de las aguas efluentes domésticas del distrito de Lunahuaná usando los datos de la tabla 17.

Tabla 18. Composición de nutrientes (NPK) del bioabono y las aguas residuales municipales tratadas, del distrito de Lunahuaná.

\begin{tabular}{lcrr}
\hline \multicolumn{1}{c}{ Nutriente } & $\begin{array}{c}\text { Aporte } \\
\text { (g/hab/día) }\end{array}$ & $\begin{array}{c}\text { Aporte población } \\
\text { (g/día) }\end{array}$ & $\begin{array}{c}\text { Concentración } \\
\text { (mg/L)=ppm }\end{array}$ \\
\hline Nitrógeno amoniacal & 3 a 10 & 20700 a 69000 & 29,21 a 97,37 \\
Nitrógeno total & 6 a 12 & 41400 a 82800 & 58,42 a 117,0 \\
Fósforo total & 1 a 8 & 6900 a 55200 & 9,74 a 77,90 \\
Potasio & 2 a 6 & 13800 a 41400 & 19,47 a 58,42 \\
Detergentes & 7 a 12 & 48300 a 82800 & 68,16 a 116,85 \\
Cloruros & 5 a 10 & 34500 a 69000 & 48,69 a 97,37 \\
Quistes, hongos y bacterias & ----- & - & esterilizado \\
\hline
\end{tabular}

Fuente: Elaboración propia

Tabla 19. Comparación de la composición de la solución hidropónica La Molina® y del bioabono producido en la Planta de Tratamiento de Aguas Residuales (PTAR).

\begin{tabular}{|c|c|c|}
\hline Componente & $\begin{array}{c}\text { Solución nutritiva } \\
\text { hidropónica La Molina }{ }^{8}\end{array}$ & $\begin{array}{c}\text { Bioabono líquido obtenido } \\
\text { en la PTAR }\end{array}$ \\
\hline $\begin{array}{l}\mathrm{N}(\mathrm{ppm}) \\
\mathrm{P}(\mathrm{ppm}) \\
\mathrm{K}(\mathrm{ppm}) \\
\mathrm{Ca} a^{(*)}(\mathrm{ppm}) \\
\mathrm{S}^{(*)}(\mathrm{ppm}) \\
\mathrm{Mg}^{(*)}(\mathrm{ppm}) \\
\mathrm{Fe}(\mathrm{ppm}) \\
\mathrm{Mn}(\mathrm{ppm}) \\
\mathrm{B}^{(*)}(\mathrm{ppm}) \\
\mathrm{Zn}(\mathrm{ppm}) \\
\mathrm{Cu}(\mathrm{ppm}) \\
\mathrm{Mo}(\mathrm{ppm})\end{array}$ & $\begin{array}{r}190 \\
35 \\
210 \\
150 \\
70 \\
45 \\
1.00 \\
0.50 \\
0.50 \\
0.15 \\
0.10 \\
0.05\end{array}$ & $\begin{array}{r}\text { 58,4 - 117,00 } \\
9,74 \text { - 77,90 } \\
\text { 19,47 - 58,42 } \\
------- \\
------ \\
----- \\
------ \\
----- \\
----- \\
------ \\
----- \\
------\end{array}$ \\
\hline
\end{tabular}

$1 \mathrm{ppm}$ (una parte por millón) = $1 \mathrm{mg} /$ Litro

(*): Incluye las cantidades que aporta el agua.

Fuente: Universidad Nacional Agraria La Molina, (2012)

Tabla 20. Estimación de precios unitarios de la solución nutritiva hidropónica La Molina ${ }^{\circledR}$

\begin{tabular}{cccc}
\hline $\begin{array}{c}\text { Precio de la } \\
\text { solución } \\
\text { (S/.) }\end{array}$ & $\begin{array}{c}\text { Volumen de la } \\
\text { solución nutritiva } \\
\text { (L) }\end{array}$ & $\begin{array}{c}\text { Precio de la } \\
\text { solución nutritiva }\left(^{*}\right) \\
\text { (S/.) }\end{array}$ & $\begin{array}{c}\text { Precio unitario de la } \\
\text { solución nutritiva } \\
\text { (S/./L) }\end{array}$ \\
\hline $15.00^{(1)}$ & 200 & 15,20 & 0,076 \\
$85.00^{(1)}$ & 1600 & 86,60 & 0,054 \\
$45.00^{(1)}$ & 1000 & 46,00 & 0,046 \\
\hline
\end{tabular}

$\left.{ }^{*}\right)$ : Se ha considerado el precio del agua en $1,00\left(\mathrm{~S} / . / \mathrm{m}^{3}\right)$

(1)Fuente: Universidad Nacional Agraria La Molina, (2012) 
Como precio referencial para el bioabono producido en la PTAR asumimos el valor 0,076 (S/./L). Asumimos el valor más alto, dado que el bioabono PTAR posee la cualidad adicional de ser estéril.

Siendo el agua residual municipal tratada de características similares a un biol, es una fuente orgánica de fitorreguladores en pequeñas cantidades, y es capaz de promover actividades fisiológicas y estimular el desarrollo de las plantas, sirviendo para: enraizamiento (aumenta y fortalece la base radicular), acción sobre el follaje (amplía la base foliar), mejora la floración y activa el vigor y poder germinativo de la semilla, traduciéndose todo esto en un aumento significativo de las cosechas.
El bioabono de la PTAR, por tener la calidad de estéril, podrá ser aplicado para abonar las plantas cultivadas en el interior del hogar y en jardinería del hogar.

\section{Estimación de ingresos en el horizonte del proyecto}

Vamos a considerar que la producción de bioabono es igual a la producción del agua efluente de la PTAR y esta es directamente proporcional a la población. En la tabla 21, se muestran los ingresos brutos por producción de bioabono PTAR, considerando un precio de $0,076(\mathrm{~S} / . / \mathrm{L})$ y una tasa de interés anual de $9 \%$.

Tabla 21. Estimación de Ingresos del proyecto en el horizonte del proyecto.

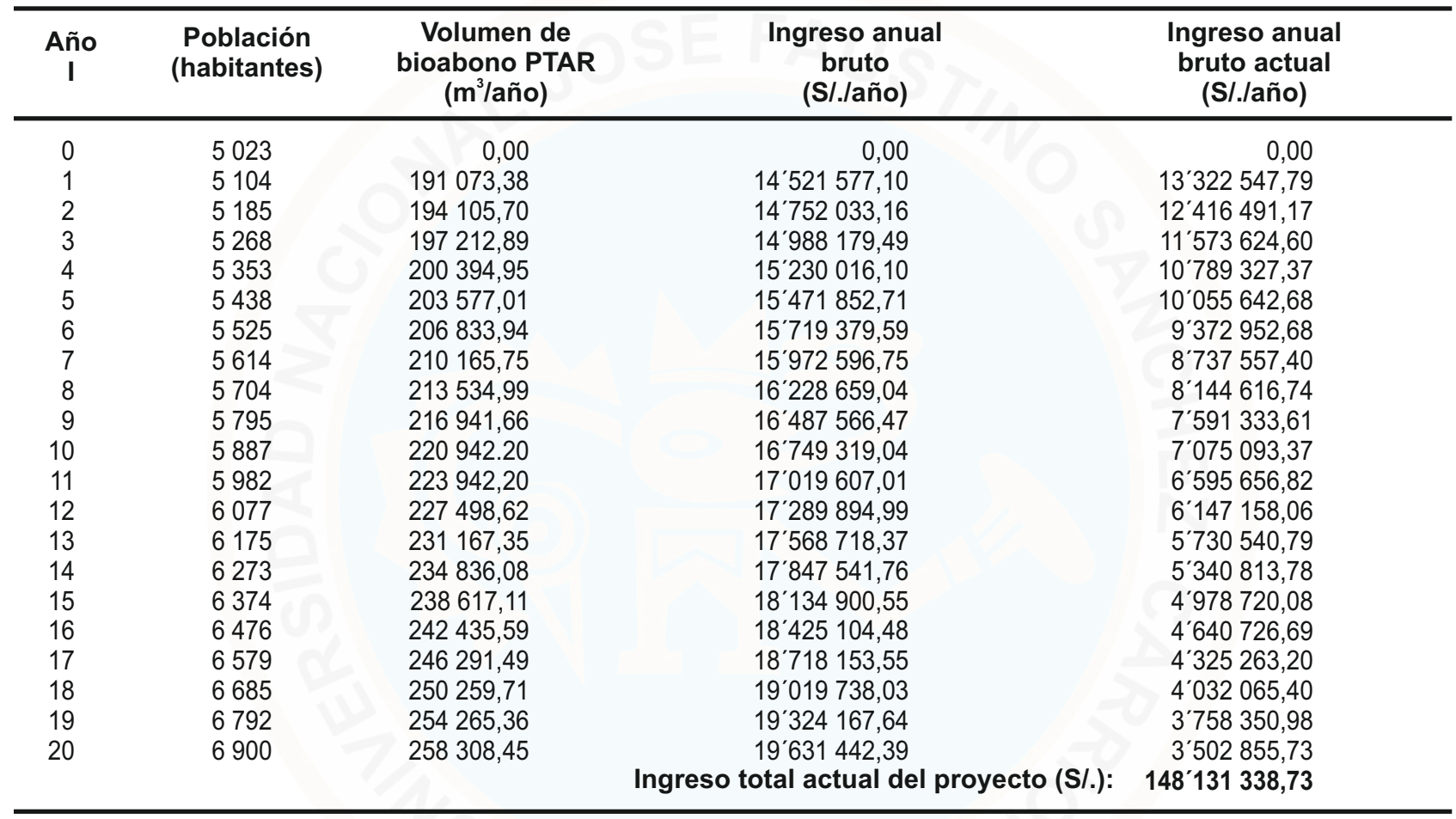

Fuente: Elaboración propia

\section{Beneficios sociales del proyecto}

1. Beneficios en salud: El desarrollo del proyecto tendrá un impacto directo en la erradicación de enfermedades del sistema respiratorio, enfermedades digestivas, enfermedades parasitarias, enfermedades de la piel y tejido subcutáneo, en el distrito. Disminuyendo, en el mejor de los casos, las enfermedades en aproximadamente el $67 \%$ de la morbilidad actual.
2. Beneficios en agricultura: Para apoyar esta labor de agricultura, se podrá destinar parte del bioabono producido para regar los cultivos. Tomamos como referencia el cultivo de fresa que es el que demanda mayor cantidad de bioabono (480 L/Ha/semana), para estimar la cantidad de bioabono que se destinaría anualmente, para riego.

El volumen de bioabono líquido producido en el horizonte de proyecto es $\mathrm{V}=4$ 461'848,010 (L). Este volumen debe ser igual al producto de la intensidad de riego $(R)$, por área de riego $(A)$, por el tiempo de riego $(T)$.

$$
V(L)=R\left(\frac{L}{H a \text { sem }}\right) A(H a) T(a n ̃ o)
$$

$$
\mathrm{A}(\mathrm{Ha}) \mathrm{T}(\mathrm{año})=\frac{\mathrm{V}(\mathrm{L})}{\mathrm{R}\left(\frac{\mathrm{L}}{\mathrm{Ha} \mathrm{sem}}\right)\left(\frac{52 \mathrm{sem}}{\text { año }}\right)}=\frac{4461^{\prime} 848,010(\mathrm{~L})}{480\left(\frac{\mathrm{L}}{\text { Ha sem }}\right)\left(\frac{52 \mathrm{sem}}{\text { año }}\right)}=178 \text { 754,94 (Ha año) }
$$




\section{Big Bang Faustiniano}

\section{Vicerrectorado de Investigación}

El distrito de Lunahuaná consumiría en el horizonte del proyecto.

$$
A T=400(\mathrm{Ha}) 20 \text { (año) }=8000 \text { (Ha año) }
$$

Que equivale al $4,48 \% \approx 4,5 \%$ de la capacidad de la PTAR. La producción restante $(\approx 95,5 \%)$, podría comercializarse con los agricultores de la provincia de Cañete o para ampliar las actividades agrícolas del distrito.

\section{REFERENCIAS BIBLIOGRÁFICAS}

Andrade, S. (2002). Preparación y Evaluación de Proyectos. Lima: Lucero S. R.L.

Constructora Grupo S10 (2013). Costos construcción arquitectura e Ingeniería. Lima, Perú, edición 232, Julio 2013.

Electron beam tecnology ebTech 550 yongsan-dong Yuseong-gu, Daejeon 305-500, Korea, (2009). diapositiva de exposición "International Topical Meeting on Nuclear Research Applications and Utilization of Accelerators Vienna, Austria 4 - 8 May 2009". [Citado el 02 de Nov del 2011]. Disponible en: http://www.pub.iaea.org/MTCD/publications/PDF/P14 33_CD/datasets/presentations/SM-EB-23.pdf

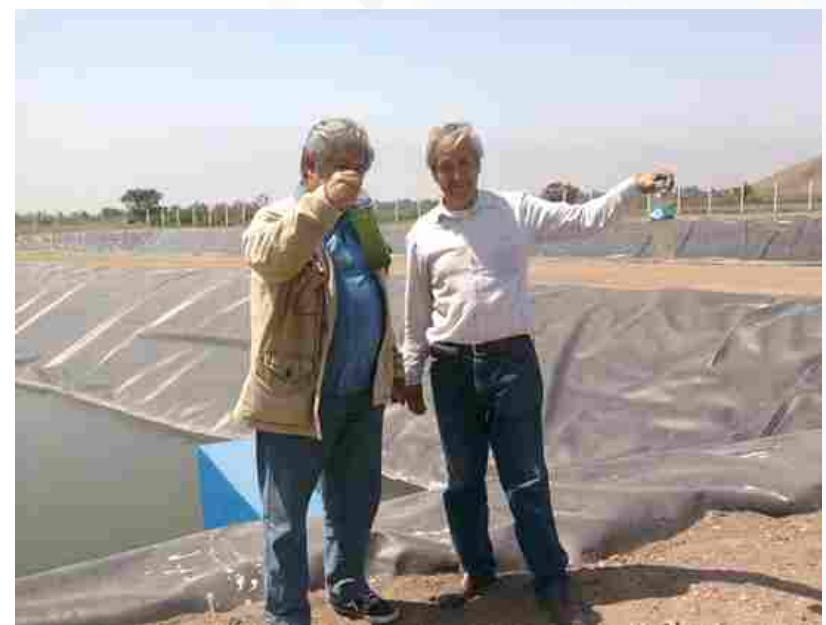

Figura 1. Observando las muestras recogidas de aguas residuales (planta de tratamiento de aguas residuales de Quilmaná).

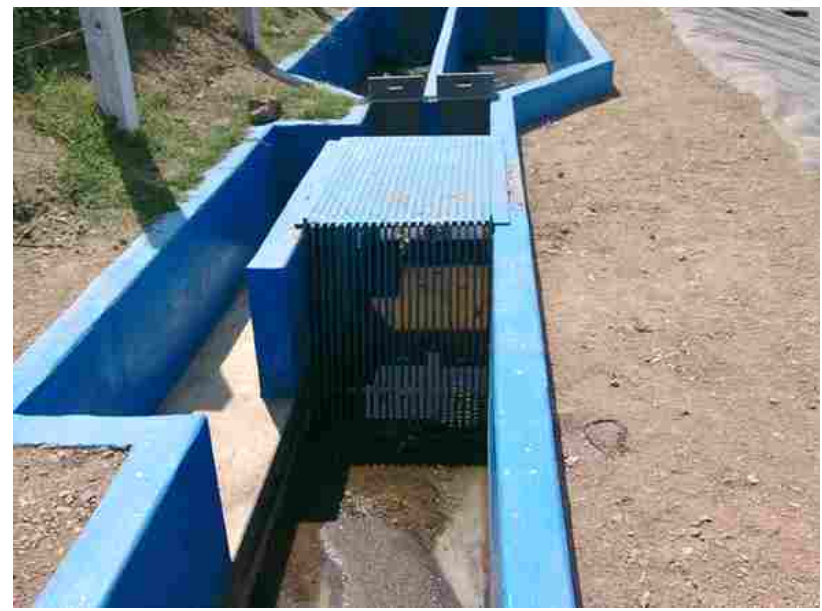

Figura 3. Rejas de desbaste y desarenador de la PTAR de Quilmaná.
Moreno, J. (2010). Subgerencia de desarrollo urbano, Municipalidad distrital de Nuevo Imperial, Proyecto de Inversión Pública: "Rehabilitación y mejoramiento del sistema de alcantarillado y tratamiento de aguas residuales en el Cercado de Lunahuaná, distrito de Lunahuaná - Cañete - Lima", Código SNIP 17006, viable, Lunahuaná, 2010.

Rojas Vargas, Ricardo. (2002). Coordinador de Proyectos Especiales CEPIS/OPS-OMS. Conferencia Sistemas de Tratamiento de Aguas Residuales, Curso Internacional "Gestión integral de tratamiento de aguas residuales". Centro Panamericano de Ingeniería Sanitaria y Ciencias del Ambiente. División de Salud y Ambiente. Organización Panamericana de la Salud. Organización Mundial de la Salud, 2002.

Universidad Nacional Agraria La Molina, Centro de Investigación de Hidroponía y Nutrición Mineral. [Citado el 05 de Marzo, 2012]. Disponible en: http://www.lamolina.edu.pe/hidroponia/solucion1.htm

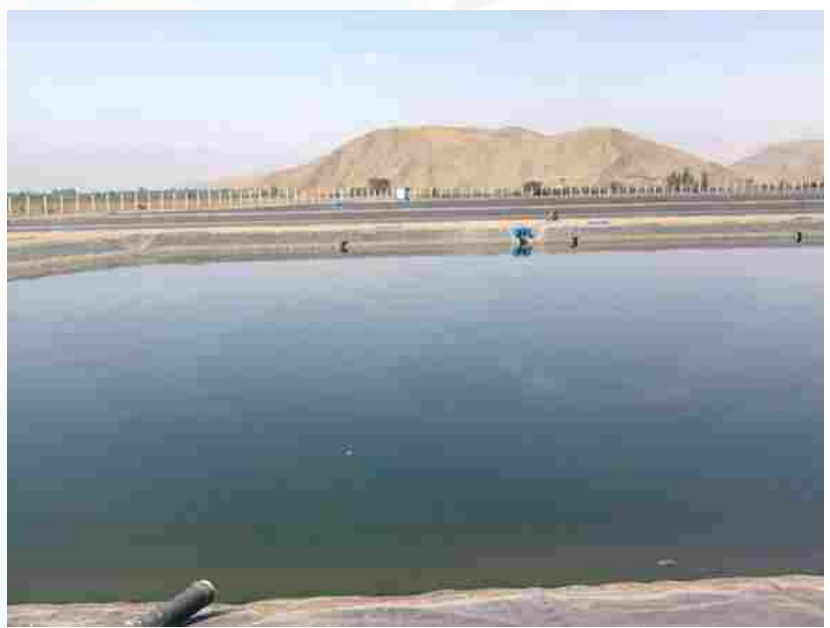

Figura 2. Entrada a la laguna de aireación y conexión con la siguiente laguna (PTAR de Quilmaná).

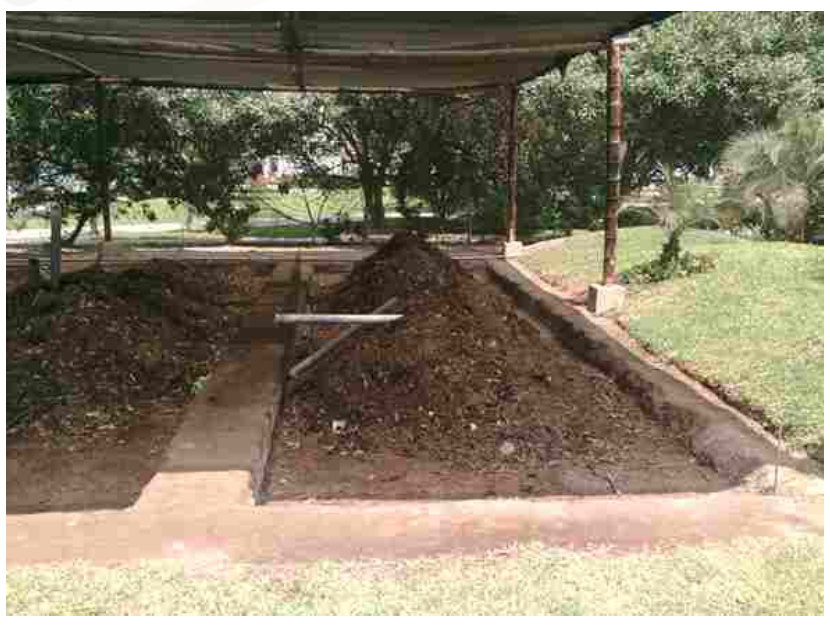

Figura 4. Preparación de humus a partir de desechos orgánicos vegetales (podas de parques y jardines) en el Parque Ecológico de la Municipalidad de San Borja. 